\title{
Determining Physiological and Psychological Predictors of Time to Task Failure on a Virtual Reality Sørensen Test in Participants With and Without Recurrent Low Back Pain: Exploratory Study
}

Megan E Applegate ${ }^{1}$, PhD; Christopher R France ${ }^{2}$, PhD; David W Russ ${ }^{3,4}$, PT, PhD; Samuel T Leitkam ${ }^{5}$, PhD; James $\mathrm{S}$ Thomas ${ }^{3}, \mathrm{PT}, \mathrm{PhD}$

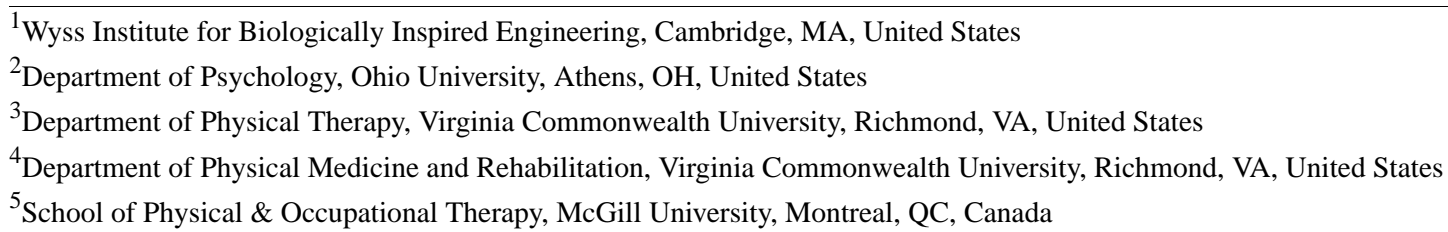

\section{Corresponding Author:}

Megan E Applegate, $\mathrm{PhD}$

Wyss Institute for Biologically Inspired Engineering

60 Oxford Street

Cambridge, MA, 02138

United States

Phone: 18154746743

Email: applegate@seas.harvard.edu

\begin{abstract}
Background: Sørensen trunk extension endurance test performance predicts the development of low back pain and is a strong discriminator of those with and without low back pain. Performance may greatly depend on psychological factors, such as kinesiophobia, self-efficacy, and motivation. Virtual reality video games have been used in people with low back pain to encourage physical activity that would otherwise be avoided out of fear of pain or harm. Accordingly, we developed a virtual reality video game to assess the influence of immersive gaming on the Sørensen test performance.

Objective: The objective of our study was to determine the physiological and psychological predictors of time to task failure (TTF) on a virtual reality Sørensen test in participants with and without a history of recurrent low back pain.

Methods: We recruited 24 individuals with a history of recurrent low back pain and 24 sex-, age-, and body mass index-matched individuals without a history of low back pain. Participants completed a series of psychological measures, including the Center for Epidemiological Studies-Depression Scale, Pain Resilience Scale, Pain Catastrophizing Scale, Tampa Scale for Kinesiophobia, and a self-efficacy measure. The maximal isometric strength of trunk and hip extensors and TTF on a virtual reality Sørensen test were measured. Electromyography of the erector spinae, gluteus maximus, and biceps femoris was recorded during the strength and endurance trials.

Results: A two-way analysis of variance revealed no significant difference in TTF between groups $(P=.99)$, but there was a trend for longer TTF in females on the virtual reality Sørensen test $(P=.06)$. Linear regression analyses were performed to determine predictors of TTF in each group. In healthy participants, the normalized median power frequency slope of erector spinae (beta $=.450$, $P=.01$ ), biceps femoris (beta $=.400, P=.01$ ), and trunk mass (beta $=-.32, P=.02$ ) predicted TTF. In participants with recurrent low back pain, trunk mass (beta=-.67, $P<.001$ ), Tampa Scale for Kinesiophobia (beta=-.43, $P=.01$ ), and self-efficacy (beta $=.35$, $P=.03$ ) predicted TTF.

Conclusions: Trunk mass appears to be a consistent predictor of performance. Kinesiophobia appears to negatively influence TTF for those with a history of recurrent low back pain, but does not influence healthy individuals. Self-efficacy is associated with better performance in individuals with a history of recurrent low back pain, whereas a less steep median power frequency slope of the trunk and hip extensors is associated with better performance in individuals without a history of low back pain.
\end{abstract}

(JMIR Serious Games 2018;6(3):e10522) doi: 10.2196/10522 


\section{KEYWORDS}

fatigue; low back pain; Sørensen test; trunk mass; virtual reality

\section{Introduction}

Low back pain (LBP) represents a significant societal and economic burden [1] with direct medical costs approaching US $\$ 100$ billion annually in the United States alone [2]. These costs are driven primarily by the $10 \%-15 \%$ of individuals who develop chronic LBP $[1,3]$. Poor trunk extension endurance has been identified as a risk factor for the development of LBP [4]. Specifically, poor time to task failure (TTF) on the Sørensen back extension endurance test, which requires an individual to maintain the upper body in an unsupported horizontal position to the point of fatigue, predicts first-time episodes of LBP $[5,6]$ and chronic LBP [7]. Although the Sørensen test has been used for the identification of LBP risk, the underlying mechanisms driving poor performance on the test are not well understood. Research has demonstrated that in addition to physiological factors, such as median power frequency (MPF) slopes of the trunk and hip extensors and anthropometrics, psychological factors must be considered in the assessment of performance on the Sørensen test.

Evidence suggests that individuals terminate the Sørensen test for reasons other than subjective fatigue; these reasons include pain, discomfort, fear, and lack of motivation [8]. Studies of rehabilitation motivation in clinical populations, such as those of individuals recovering from cardiac events, have demonstrated that although motivation is difficult to define and measure, it plays a crucial role in rehabilitation outcomes for patients [9]. Motivation could be manipulated through the use of distracting, immersive virtual reality gaming. Virtual reality games have been implemented for pain distraction in individuals receiving chemotherapy and during burn debridement, resulting in lower pain ratings and greater tolerance of treatments [10-12] and encouraging greater lumbar spine flexion in individuals with kinesiophobia and LBP [13]. Thus, by providing a distraction element to counteract fear cognitions during the assessment, a virtual reality video game could enhance motivation during the Sørensen test, leading to maximal effort.

However, psychological factors are likely still involved in performance on the Sørensen test. Self-efficacy contributes to the performance of physical activities. Self-efficacy is the magnitude of belief in one's ability to perform a certain task to achieve a specific outcome [14]. Self-efficacy is strongly associated with sports performance [15]. Although the study of self-efficacy regarding physical activity contributes to the understanding of human behavior, application to the Sørensen test, specifically, is limited.

The influence of fear of pain may vary as a function of prior LBP experience. Chronic pain is a biopsychosocial phenomenon; an individual's emotions and appraisal of pain contributes to chronicity [16]. Cognitive appraisal of pain varies based on individuals' beliefs about their ability to cope with pain. In many situations, pain can elicit negative emotional reactions that lead to the amplification of pain experiences [17]. Individuals with maladaptive emotional responses to pain who undergo traditional treatment for LBP may continue to experience pain and disability long after the symptoms are treated. A cognitive behavioral model of chronic LBP, termed the fear-avoidance model, explains the progression from acute pain to chronic pain and disability [18,19]. In addition, the model hypothesizes that an individual's pain experience depends upon their established levels of pain-related fear. Kinesiophobic individuals, those who are prone to avoidance of movement for fear of pain or harm, respond to pain with catastrophic thoughts (ie, "The pain will get worse if I attempt to overcome it"), leading to inactivity and further progression of disability $[18,20]$.

Measures of kinesiophobia have been used to predict LBP [19]. Pain-related fear predicts reduced maximal force production and increased pain-related interference in daily activities, regardless of actual pain levels [21]. Moreover, kinesiophobia has been recognized as an integral factor in Sørensen test performance. Sørensen TTF "underperformance" in individuals with chronic LBP could be predicted, in part, by fear-avoidance beliefs, as well as self-efficacy [22].

A variation of the Sørensen test that uses a virtual reality video game could encourage maximal effort, counteract fear cognitions, and allow for more accurate identification of both the physiological and psychological factors driving performance. Accordingly, we have developed a variation of the Sørensen test that uses a virtual reality video game to provide motivation and distraction. This study aims to determine whether the use of a virtual reality video game influences performance on the Sørensen test and whether the predictors of TTF vary between individuals with and without recurrent LBP on the virtual reality Sørensen test.

\section{Methods}

\section{Participants}

A sample of 24 individuals (12/24, 50\% male) with a history of recurrent LBP (LBP) and 24 individuals (12/24, 50\% male) with no history of LBP (Healthy) matched for age, sex, and body mass index (BMI) were recruited from the Ohio University student population and surrounding community for this comparative study. Table 1 summarizes the participants' characteristics. Individuals with a history of hip arthroscopy or spine surgery, known neurological, visual, or orthopedic impairments, depression, ongoing drug or alcohol problems, elevated resting blood pressure $(>135 />90 \mathrm{mmHG})$, or BMI of $>35$ were excluded from the study. We defined LBP history as having experienced more than one episode of LBP with symptoms occurring in the past 6 months and a previous consultation regarding their LBP symptoms with a health care provider; participants reporting moderate to severe pain (numerical pain rating scale of $>3$ ) within the past 6 weeks or those who did not meet the classification of category 1 (LBP that does not radiate) through category 3 (LBP that radiates beyond the knee but without neurological signs) on the Classification System of the Quebec Task Force on Spinal Disorders were excluded from participation. The protocol was 
approved by the Ohio University Institutional Review Board for human subjects research, and all individuals provided written consent prior to participation.

\section{Instruments}

\section{Center for Epidemiological Studies-Depression Scale}

The Center for Epidemiological Studies-Depression Scale (CES-D) was used in the general population to measure depressive symptomatology. Good predictive validity for the identification of depression in individuals with chronic pain has been established [22] as well as good sensitivity (93.2\%) using a cutoff score of 19 (out of 60) for the identification of depression in individuals with chronic pain [23].

\section{Pain Catastrophizing Scale}

The Pain Catastrophizing Scale (PCS) is a 13-item scale that measures pain catastrophizing by assessing the degree to which the respondent experiences specific thoughts and feelings during pain on a 5-point Likert-type scale with the endpoints "Not at all" (0) and "All the time" (4) with a score of 30 indicating clinically relevant pain catastrophizing behavior. PCS has been identified as a reliable and valid measure of pain catastrophizing (Cronbach alpha $=.87$; test-retest intraclass correlation coefficient=.93). PCS is consistently associated with pain sensitivity and pain-related distress in experimental pain studies [24-26]. Furthermore, pain catastrophizing is a primary vulnerability construct $[27,28]$.

\section{Pain Resilience Scale}

The Pain Resilience Scale (PRS) asks participants how they respond when faced with intense or prolonged pain by rating items on a 14-item Likert scale using a "Not at all" (0) to "All the time" (4) scale with higher scores indicating greater pain resilience. Strong internal consistency and acceptable levels of stability have been established (alpha=.93, intraclass correlation coefficient $=.80$ ) [29].

\section{Tampa Scale for Kinesiophobia and Tampa Scale for Kinesiophobia-General Population}

Two versions of the Tampa Scale for Kinesiophobia (TSK) were used in this study, each using 17 items on a 4-point Likert scale ranging from "Strongly disagree" (1) to "Strongly agree" (4) with scores $>36$ indicating clinically relevant kinesiophobia. The LBP group completed the standard TSK, which assessed fear of movement at the risk of injury or (re)injury. The healthy group completed the TSK-General Population (TSK-G), which used items modified to ask how much the respondent would fear movement at the risk of injury or (re)injury if they had
LBP. In addition, construct validity and predictive ability has been established in LBP populations [30]. In the general population, TSK-G is also reliable and valid as a self-report measure of fear of movement and (re)injury [31].

\section{Self-Efficacy Measure}

The self-efficacy measure was developed for this study based on prior studies [32,33]. After practicing the task position for a brief period, participants were asked to indicate their confidence in their ability to maintain the Sørensen test position for 1, 2, 3, and 4 minutes on a scale ranging from "Not at all confident" (0) to "Highly confident" (100).

\section{Data Collection}

Participants completed 2 separate testing sessions. Participants in this study were first included in an assessment of performance on the classic Sørensen test [34] and were invited to participate in the virtual reality Sørensen test 3-14 days later. During the first testing session, participants completed the psychological surveys, maximal strength assessments, and the classic Sørensen test. During the second testing session, participants completed the virtual reality Sørensen test.

\section{Electromyography Data}

Electromyography (EMG) was performed as described previously [34]. In brief, EMG was collected using a 16-channel Delsys Bagnoli system (Delsys Inc, Boston, MA, USA; bandwidth $20-450 \mathrm{~Hz}$ ); the bar leads were modified with clip leads to allow attachment to $\mathrm{Ag}-\mathrm{Ag} \mathrm{Cl}$ surface electrodes over the erector spinae (ERS) at the L2 and L4 level aligned between the posterior superior iliac spine and the lateral border of the muscle at the 12th rib, gluteus maximus midway between the greater trochanter and the posterior superior iliac spine, and long head of the biceps femoris (BF) midway between the fibular head and the ischial tuberosity. The raw surface EMG data were amplified $(1 \mathrm{k})$ and $\mathrm{A} / \mathrm{D}$ converted with 16-bit resolution, sampled at $1000 \mathrm{~Hz}$, and averaged across sides for each muscle.

\section{Median Power Frequency}

MPF was calculated as described previously [35]. Using a fast Fourier transformation with a 512-point Hamming window, the EMG power spectrum for each muscle was calculated. MPF was determined using a 2-second moving window with $50 \%$ overlap. The normalized slope of MPF was determined as follows: (MPF slope/initial MPF)x100 [35]. All processing of EMG data were performed with custom software written in MATLAB (Version 2016b; The MathWorks).

Table 1. Participant characteristics.

\begin{tabular}{lll}
\hline Characteristics & Healthy $(\mathrm{n}=24)$, mean $(\mathrm{SE})$ & Low back pain $(\mathrm{n}=24)$, mean $(\mathrm{SE})$ \\
\hline Age $($ years $)$ & $29.2(2.2)$ & $24.3(1.5)$ \\
Height $(\mathrm{m})$ & $1.7(0.0)$ & $1.7(0.0)$ \\
Weight $(\mathrm{kg})$ & $73.3(2.6)$ & $71.4(2.6)$ \\
Body mass index $\left(\mathrm{kg} / \mathrm{m}^{2}\right)$ & $24.8(0.7)$ & $24.2(0.7)$ \\
\hline
\end{tabular}




\section{Force Output and Torque Moment Data}

The maximal voluntary contraction data were measured as described previously [34]. In brief, our custom articulated fatigue table integrated a 6 degree of freedom (DOF) load cell (MC5-1250; AMTI, Watertown, MA, USA) into the trunk platform connected to a signal conditioner (GEN 5; AMTI), and single DOF load cell (XTS4-500; Load Cell Central, Milan, PA, USA) into the leg brace connected to an analog signal conditioner (OM19; Load Cell Central). Force and torque data were A/D converted at 16-bit resolution and sampled at 1000 $\mathrm{Hz}$.

\section{Position Data}

The trunk position during the Sørensen test was measured as described previously [34]. In brief, custom-made potentiometers were anchored over the participant's sacrum at the level of L5-S1 and trunk at the level of T12-L1. An algorithm converted the potentiometers' voltages into position (degrees of rotation) with excellent linearity of fit $\left(R^{2}=0.9988\right)$. Our custom LABVIEW (Version 13; National Instruments, Austin, TX, USA) program used the algorithm to track the position during the Sørensen tests. The horizontal position was individually calibrated prior to each test.

\section{Maximal Voluntary Contraction Procedure}

The maximal voluntary contraction procedure was completed as described previously [34]. As illustrated in Figure 1, subjects were situated on the custom fatigue table with the anterior superior iliac spine aligned with the edge of the table and the torso supported by the platform positioned such that the trunk center of mass was centered over the 6 DOF load cell. In addition, the torso was secured to the platform, the pelvis was secured to the table, and the lower legs were secured at $33 \%$ of hip height by a padded bar connected to the single DOF load cell. Bracing of the feet was inhibited with a foam roll placed below the ankles. The trunk mass was measured in this position. EMG was measured as previously described and the custom LABVIEW (Version 13; National Instruments) program collected EMG and load cell measurements.

For the trunk extension trials, participants were instructed to pull their torso up into the back restraint. Three submaximal trunk extension attempts of increasing intensity were followed by 3 maximal trunk extension attempts. Then, participants were instructed to extend their legs up against the stationary leg restraint; 3 submaximal hip extension attempts of increasing intensity were followed by 3 maximal attempts. We provided 2 minutes of rest between each attempt. Verbal encouragement and visual and audio feedback were provided via the custom LABVIEW (Version 13; National Instruments) program.

\section{Virtual Reality Sørensen Procedure}

The participants performed the virtual reality Sørensen test on a standard table with belts across the pelvis and calves at $33 \%$ of hip height, the anterior superior iliac spine aligned with the edge of the table, and the upper body unsupported, as seen in Figure 2. Subjects wore an Oculus Rift head mounted display (Oculus Rift Developers Kit 2), as shown in Figure 2. During the test, the Oculus Rift displayed a sky environment in which the participant attempted to "fly" through hoops, as seen in Figure 3. Extending and flexing the trunk appeared to make the subject fly higher and lower, respectively. The hoops were positioned such that the participants were encouraged to maintain a horizontal position for as long as possible. Immediately following a brief practice attempt of $<5$ seconds, participants completed the self-efficacy questionnaire.

Figure 1. Experimental setup on the fatigue table for maximal voluntary contraction of the trunk and hip.

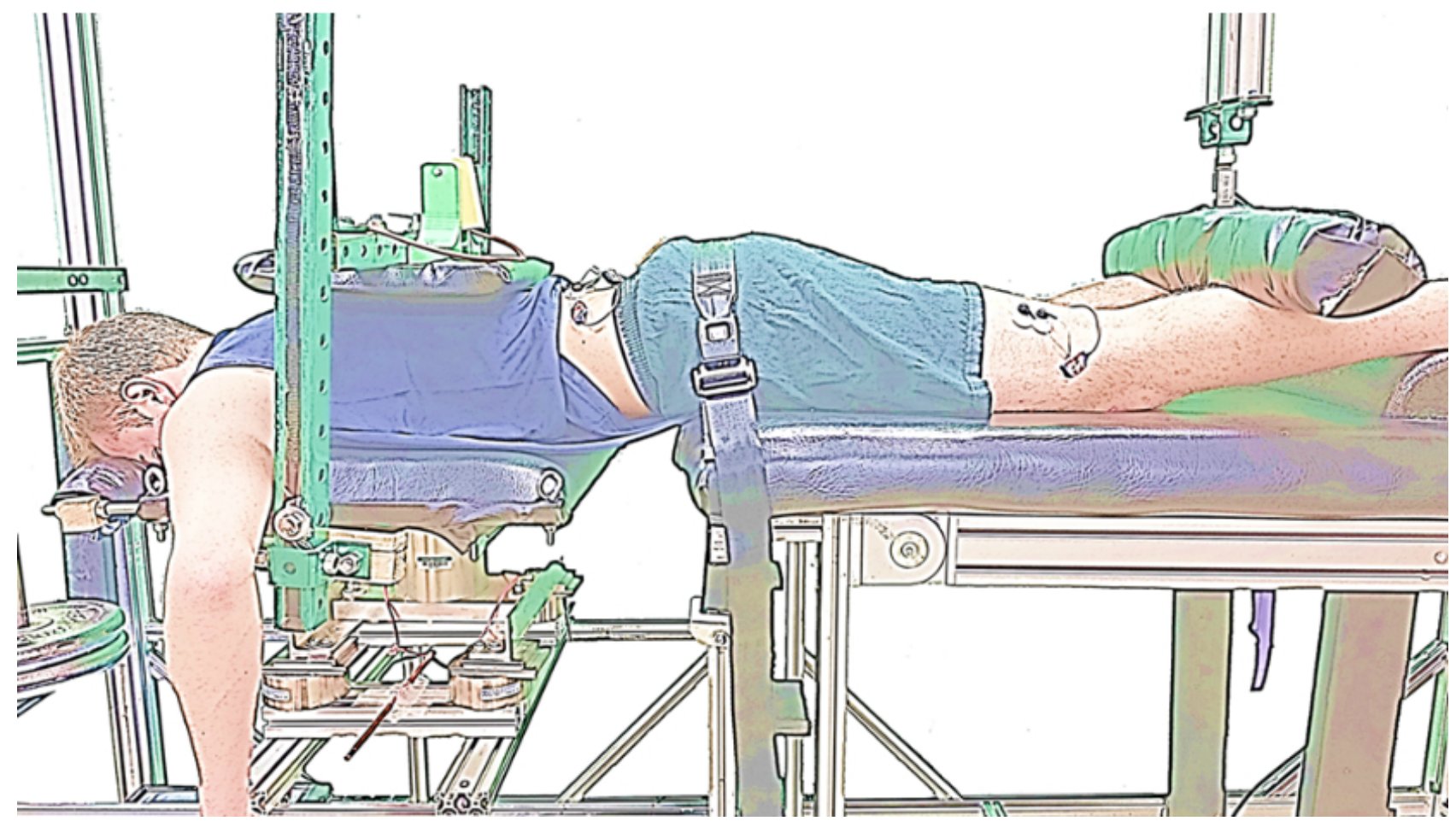


Figure 2. Experimental setup on the standard table for the virtual reality Sørensen test.

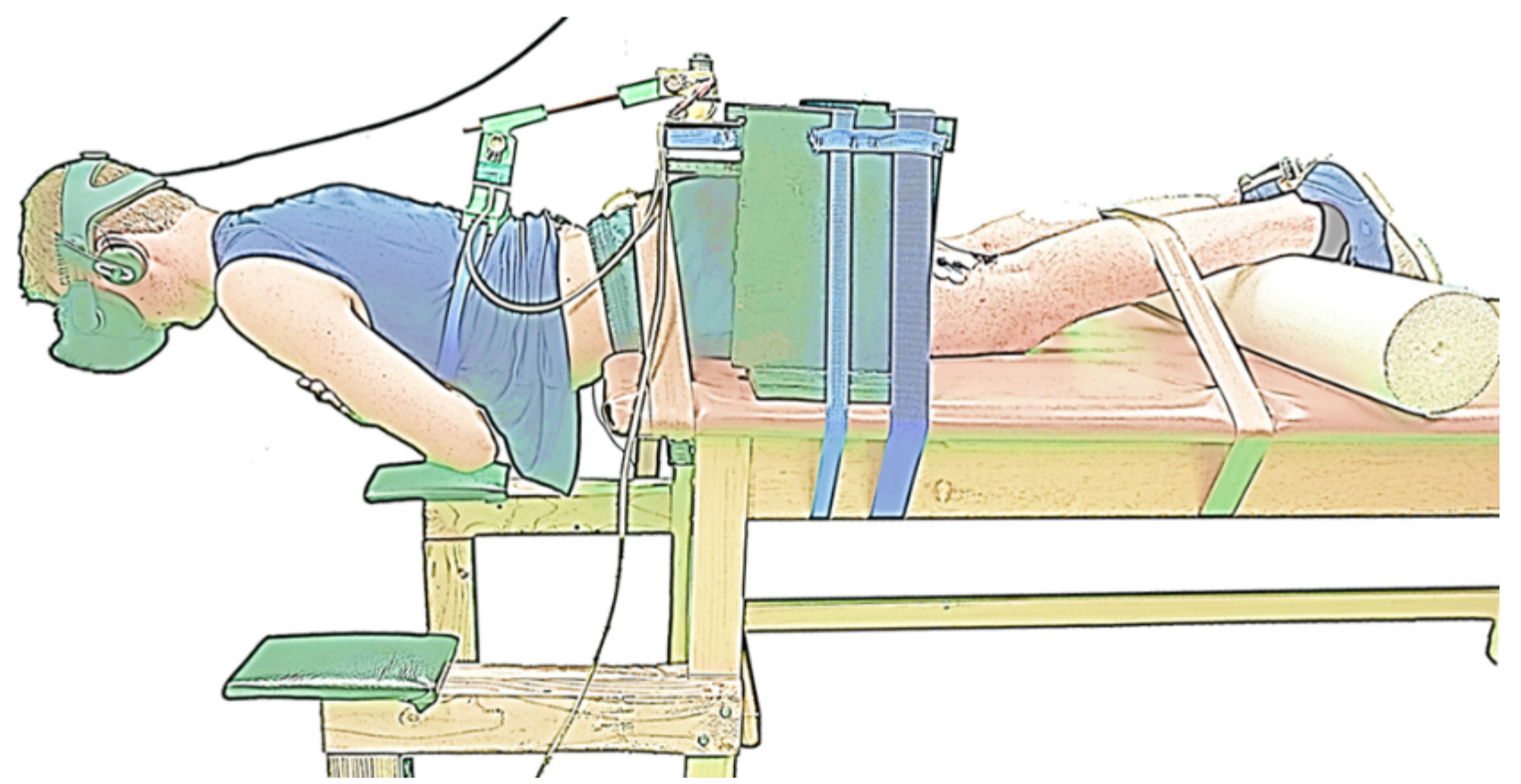

Figure 3. Participant's perspective during gameplay, displayed through the Oculus Rift headset.

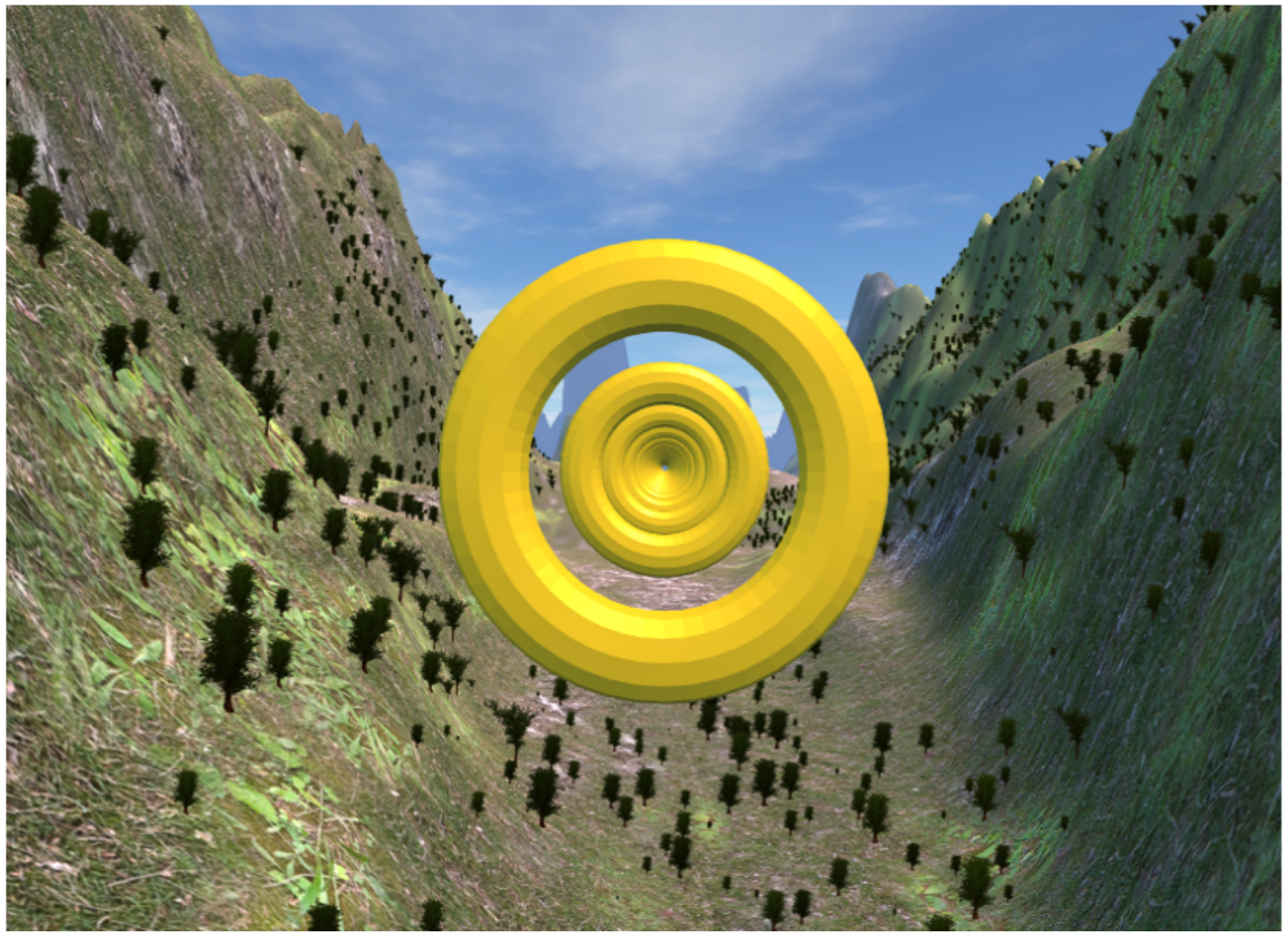

Participants then attempted to maintain the task position until failure while receiving audio and visual feedback through the virtual reality video game; a tone played when the participant's position was $>2^{\circ}$ beyond the target position in either direction, which was visually represented by flying above or below the hoops. The trial was terminated when participants fell out of the range $\left( \pm 2^{\circ}\right)$ for $>3$ consecutive seconds.

\section{Statistical Analysis}

In this study, independent-sample $t$ tests were used to evaluate differences in participant demographics. A two-way analysis of variance was used to determine group and sex differences in TTF on the virtual reality Sørensen test. In addition, stepwise linear regression analyses were performed to determine which physiological factors were related to TTF on the virtual reality Sørensen test in each group. The second set of linear regression analyses was performed with the significant physiological 
factors entered into the first block and psychological factors entered stepwise in the second block to determine which psychological factors were related to TTF on the virtual reality Sørensen test in each group. All analyses were performed in SPSS (IBM Corp.), and results are reported as mean (SE) unless otherwise stated.

\section{Results}

\section{Demographics}

The independent-sample $t$ test revealed no significant differences between Healthy and LBP groups with one exception; the depression scores were significantly higher in the LBP group than in those the healthy group (Table 2).

\section{Time to Task Failure}

A 2 Group (Healthy, LBP) x 2 Sex (Male, Female) two-way analysis of variance revealed no significant differences in group $\left(F_{1,44}=0.00, P=.99\right)$ or group by sex $\left(F_{1,44}=0.33, P=.57\right.$; Table $3)$; however, there was a marginal effect of sex $\left(F_{1,44}=3.89\right.$, $P=.06$ ), which reflected a tendency toward the longer TTF in female versus male participants.

\section{Predictors of Virtual Reality Sørensen Time to Task Failure}

Simple correlations were run between TTF and each of the physiological and psychological factors that were entered into the linear regression analyses. Table 4 displays the Pearson correlations.

\section{Healthy}

A stepwise linear regression analysis identified the normalized MPF slope of ERS (beta=.45, $P=.01$ ), normalized MPF slope of $\mathrm{BF}$ (beta=.40, $P=.01$ ), and trunk mass (beta=-.32, $P=.03$ ) as significant predictors of TTF. A separate linear regression analysis was then run with the MPF slopes of ERS and BF; trunk mass was entered into the first block and all psychological measures (ie, CES-D, TSK, self-efficacy, PCS, and PRS) were offered stepwise into the second block. Only trunk mass and the normalized MPF slopes of ERS and BF were retained as significant predictors of TTF on the virtual reality Sørensen test in the healthy group (Table 5).

\section{Low Back Pain}

A stepwise linear regression analysis identified the trunk mass (beta=-.53, $P=.01$ ) as a significant predictor of TTF. A separate linear regression analysis was then run with trunk mass entered into the first block, and all psychological measures (ie, CES-D, TSK, self-efficacy, PCS, and PRS) were offered stepwise into the second block. In the final model, the trunk mass (beta=-.67, $P=.001$ ), TSK (beta=-.43, $P=.01$ ), and self-efficacy (beta $=.35$, $P=.03)$ were retained as significant predictors of TTF on the virtual reality Sørensen test in the LBP group (Table 5).

Table 2. Anthropometric, strength, and psychological survey measures.

\begin{tabular}{llll}
\hline Survey measures & Healthy (n=24), mean (SE) & Low back pain (n=24), mean (SE) & $P$ value \\
\hline Trunk mass $(\mathrm{kg})$ & $36.7(1.5)$ & $35.4(1.6)$ & .54 \\
Trunk length (m) & $0.5(0.0)$ & $0.4(0.0)$ & .15 \\
Vertical trunk force (N) & $476.7(52.8)$ & $511.7(35.4)$ & .65 \\
Trunk moment (Nm) & $42.3(4.1)$ & $45.4(5.4)$ & .66 \\
Hip force (N) & $131.0(8.2)$ & $138.4(8.6)$ & .50 \\
Erector spinae MPF ${ }^{\mathrm{a}}$ slope (\%/s) & $-0.1(0.0)$ & $-0.1(0.0)$ & .32 \\
Gluteus maximus MPF slope (\%/s) & $-0.3(0.0)$ & $-0.2(0.0)$ & .16 \\
Biceps femoris MPF slope (\%/s) & $3.8(0.8)$ & $7.6(1.2)$ & .38 \\
Depression (0-60) & $39.3(2.1)$ & $37.7(2.1)$ & .01 \\
Pain resilience $(0-56)^{\mathrm{b}}$ & $7.6(1.3)$ & $6.8(0.9)$ & .61 \\
Pain catastrophizing $(0-52)^{\mathrm{b}}$ & $30.9(1.2)$ & $32.0(1.3)$ & .59 \\
Kinesiophobia (17-68) & $38.7(4.1)$ & $44.5(3.2)$ & .54 \\
\hline
\end{tabular}

${ }^{\mathrm{a}} \mathrm{MPF}$ : median power frequency.

${ }^{b}$ Ranges for the scales.

Table 3. Time to task failure on the virtual reality Sørensen test.

\begin{tabular}{llll}
\hline Participants & Healthy, mean (SE) & Low back pain, mean (SE) & Total, mean (SE) \\
\hline Male & $107.2(9.6)$ & $98.1(9.7)$ & $102.7(6.7)$ \\
Female & $128.7(21.1)$ & $137.3(17.8)$ & $133.0(13.5)$ \\
Total & $118.0(11.6)$ & $117.7(10.7)$ & $117.8(7.8)$ \\
\hline
\end{tabular}


Table 4. Simple correlations between time to task failure and factors entered into the linear regression analyses.

\begin{tabular}{|c|c|c|c|c|}
\hline \multirow[t]{2}{*}{ Measures } & \multicolumn{2}{|l|}{ Healthy } & \multicolumn{2}{|c|}{ Low back pain } \\
\hline & $r$ & $P$ value & $r$ & $P$ value \\
\hline Trunk mass & -0.467 & .02 & -0.532 & .01 \\
\hline Trunk length & 0.180 & .40 & 0.016 & .94 \\
\hline Vertical trunk force & 0.065 & .76 & -0.061 & .78 \\
\hline Trunk moment & -0.248 & .24 & -0.200 & .35 \\
\hline Hip force & -0.056 & .80 & -0.299 & .16 \\
\hline Erector spinae MPF ${ }^{\mathrm{a}}$ slope & 0.616 & .001 & 0.314 & .14 \\
\hline Gluteus maximus MPF slope & 0.440 & .03 & -0.174 & .42 \\
\hline Biceps femoris MPF slope & 0.513 & .01 & 0.418 & .04 \\
\hline Self-efficacy & 0.525 & .01 & 0.235 & .27 \\
\hline Depression & 0.128 & .55 & -0.194 & .36 \\
\hline Pain catastrophizing & -0.158 & .46 & -0.091 & .67 \\
\hline Pain resilience & -0.030 & .89 & -0.362 & .08 \\
\hline Kinesiophobia & -0.106 & .62 & -0.276 & .19 \\
\hline
\end{tabular}

${ }^{\mathrm{a}} \mathrm{MPF}$ : median power frequency.

Table 5. Significant factors identified by the linear regression analyses.

\begin{tabular}{|c|c|c|c|c|c|}
\hline Factor & Unstandardized beta & SE & Standardized beta & $t$ & $P$ value \\
\hline \multicolumn{6}{|l|}{ Healthy } \\
\hline (Constant) & 301.32 & 10.20 & - & 7.50 & $<.001$ \\
\hline Erector spinae MPF ${ }^{\mathrm{a}}$ & 140.21 & 45.17 & .45 & 3.10 & .01 \\
\hline Biceps femoris MPF & 130.24 & 44.74 & .40 & 2.91 & .01 \\
\hline Trunk mass & -1.12 & 0.49 & -.32 & -2.30 & .03 \\
\hline \multicolumn{6}{|l|}{ Low back pain } \\
\hline (Constant) & 342.21 & 61.68 & - & 5.55 & $<.001$ \\
\hline Trunk mass & -2.08 & 0.48 & -.67 & -4.34 & $<.001$ \\
\hline Kinesiophobia & -3.56 & 1.27 & -.43 & -2.81 & .01 \\
\hline Self-efficacy & 1.15 & 0.49 & .35 & 2.34 & .03 \\
\hline
\end{tabular}

${ }^{\mathrm{a}} \mathrm{MPF}$ : median power frequency.

\section{Discussion}

\section{Principal Findings}

This study aimed to examine the performance on a variation of the Sørensen test using a virtual reality video game in individuals with and without a history of recurrent LBP. To the best of our knowledge, this is the first study to use a virtual reality video game in conjunction with the Sørensen test. Contrary to much of the published literature, we did not find a significant difference in TTF between the groups. In the first longitudinal study, males with a short TTF on the Sørensen test were most likely to experience LBP in the following year, identifying the test as a predictor of first-time LBP [36]. The test was later recognized as a discriminator of those with and without LBP; individuals who had no prior LBP experience exhibited a markedly longer TTF than those with any LBP experience [37]. Many studies have reported consistent findings; however, others have failed to find a difference in performance between those with and without LBP. Many physiological factors, including the BMI, trunk mass, MPF slopes of the trunk and hip extensors, and maximal trunk and hip strength, have been found to influence the performance on the task; these factors have been discussed previously [34].

Although our sample of individuals with recurrent LBP performed just as well on the virtual reality Sørensen test as those without LBP, several interesting findings regarding the factors associated with TTF emerged. In the healthy group, it appears that TTF was driven primarily by trunk mass and the MPF slopes of the trunk and hip extensors, and this is consistent with our previous work [34]. In addition, trunk mass was a 
predictor of TTF in the LBP group. Other studies also demonstrated the marked effects of anthropometrics on performance. The workload of the task is governed by the weight of the body above the hips. It is obvious that an individual with a heavier trunk mass will not be able to maintain the test position for as long as another individual with the same strength capacity but lighter trunk mass. The effects of anthropometrics tend to be consistent in both individuals with and without LBP. Previously, marked associations have been identified between body mass, BMI, and the MPF slope of ERS in males and females with and without LBP [38]. Moreover, a marked association between TTF and torso mass in females with and without LBP has been demonstrated [39]. Trunk mass is an important factor in Sørensen test TTF, especially in those with a history of LBP, and should be considered when assessing performance. A variation in the Sørensen test that normalizes the workload to a consistent percentage of maximal strength would account for differences in trunk mass and strength to allow for a more objective assessment of endurance.

In this study, self-efficacy emerged as an important factor in Sørensen test performance. Motivation has long been recognized as a consequential factor in Sørensen test performance $[22,36,40-43]$; however, to the best of our knowledge, we are the first to attempt to manipulate it through the use of a virtual reality video game. The self-efficacy measure was created specifically for the Sørensen test task, which likely explains its strong association with TTF in the LBP group. Interestingly, self-efficacy was not predictive of performance in the healthy group. Thus, in this sample of individuals without a history of LBP, it appears that self-efficacy did not drive performance. Alternatively, our sample of individuals with a history of recurrent LBP performed better on the virtual reality Sørensen test if they reported higher ratings of confidence in their capacity to perform the task; this is consistent with our previous findings on the standard Sørensen test [34] as well as those obtained by others who found that performance was predicted, in part, by self-efficacy [22]. This would suggest that self-efficacy may be a worthwhile target for cognitive behavioral interventions for LBP.

In addition, there was a significant effect of kinesiophobia in our LBP group; those who had lower TSK scores maintained a longer TTF on the virtual reality Sørensen test; this would suggest that TSK is predictive of performance in individuals with recurrent LBP when provided with a distraction element. On the classic version of the Sørensen test [34], TSK was not predictive of performance in this same group of individuals with recurrent LBP. The virtual reality video game may have actually exacerbated fear cognitions by blocking the participant's view of the real world, reducing their sense of control, and instead redirecting focus toward their pain-related fear. Moreover, it is possible that attentional resources were reduced in response to the game. Future research could benefit from investigating the response to different types of games to determine whether certain games are more effective or whether games are not effective in any form to counteract pain-related fear.

Previous research has demonstrated an effect of sex on performance on the Sørensen test. Females tend to maintain the test position for longer than males $[43,44]$; however, several studies have found no sex differences [45,46], and others have found that males maintain the test position for longer than females [47-49]. We did identify a trend toward a sex difference on TTF with females maintaining the position slightly longer than males $(P=.06)$. Others have reported that healthy females maintained an isometric trunk extension task markedly longer than healthy males [50]. The authors attributed their results to the muscle mass and strength hypothesis, which describes the relationship among the total muscle mass, vascular compression, and the demand for oxygen. According to this hypothesis, because females typically have lower muscle mass, the vasculature is less compressed during isometric exercise, and the demand for oxygen to the active muscles is lower [51,52]. There is some evidence that females have a greater ratio of type I oxidative muscle fibers in the trunk extensors [53], which would have a greater concentration of beta- 2 adrenergic receptors, enhancing vasodilation [54]; there is also evidence that females have a greater degree of capillarization in some muscles [55], enhancing perfusion. However, others have demonstrated that intramuscular pressure may not be associated with a shift in MPF during isometric trunk extension exercises $[56,57]$. Although muscle mass was not measured in this sample, it is possible that TTF was influenced by perfusion.

\section{Limitations}

As with any study of human subjects, this study is not without its limitations. Our LBP group consisted of individuals with mild, recurrent LBP, which may have also restricted the sample to individuals with low levels of disability and pain-related fear. Individuals with higher disability and pain-related fear have poorer rehabilitation outcomes and typically perform more poorly on the Sørensen test. Thus, significant pain-related fear associations may have emerged in a sample of individuals with more severe kinesiophobia and disability symptoms. In addition, this group was primarily young, fit, college-aged students; future studies will benefit from measuring physical activity levels because cardiorespiratory fitness is likely associated with performance on any endurance task, such as the Sørensen test.

\section{Conclusions}

This study demonstrates that individuals with and without mild, recurrent LBP perform similarly on a variation of the Sørensen test using a virtual reality video game, but the underlying mechanisms driving performance vary between the groups. Performance on this variation of the Sørensen test in healthy individuals is driven primarily by physiological factors, including trunk mass and the MPF slopes of ERS and BF. In addition, trunk mass is an important factor of performance in individuals with a history of recurrent LBP; however, levels of self-efficacy and kinesiophobia also appear to be important predictors of TTF on this virtual reality Sørensen test. 


\section{Conflicts of Interest}

None declared.

\section{References}

1. Vlaeyen J, Morley S, Linton S, Boersma K, Jong J. Pain-Related Fear: Exposure-Based Treatment for Chronic Pain. Washington: IASP Press; 2012.

2. Simon LS. Relieving Pain in America: A Blueprint for Transforming Prevention, Care, Education, and Research. Mil Med 2016 Dec;181(5):397-399. [doi: 10.7205/MILMED-D-16-00012] [Medline: 27136641]

3. Freburger JK, Holmes GM, Agans RP, Jackman AM, Darter JD, Wallace AS, et al. The rising prevalence of chronic low back pain. Arch Intern Med 2009 Feb 9;169(3):251-258. [doi: 10.1001/archinternmed.2008.543] [Medline: 19204216]

4. del PB, Mocholi MH, del PJ, Parraca JA, Adsuar JC, Gusi N. Reliability and validity of lumbar and abdominal trunk muscle endurance tests in office workers with nonspecific subacute low back pain. J Back Musculoskelet Rehabil 2014;27(4):399-408. [doi: 10.3233/BMR-140460] [Medline: 24561788]

5. Hamberg-van RHH, Ariëns GAM, Blatter BM, Twisk JWR, van MW, Bongers PM. Physical capacity in relation to low back, neck, or shoulder pain in a working population. Occup Environ Med 2006 Jun;63(6):371-377 [FREE Full text] [doi: 10.1136/oem.2006.026914] [Medline: 16709701]

6. Alaranta H, Luoto S, Heliövaara M, Hurri H. Static back endurance and the risk of low-back pain. Clin Biomech (Bristol, Avon) 1995 Sep;10(6):323-324. [Medline: 11415574$]$

7. Demoulin C, Boyer M, Duchateau J, Grosdent S, Jidovtseff B, Crielaard J, et al. Is the Sørensen test valid to assess muscle fatigue of the trunk extensor muscles? J Back Musculoskelet Rehabil 2016;29(1):31-40. [doi: 10.3233/BMR-150592] [Medline: 25812550]

8. Ropponen A, Gibbons LE, Videman T, Battié MC. Isometric back extension endurance testing: reasons for test termination. J Orthop Sports Phys Ther 2005 Jul;35(7):437-442. [doi: 10.2519/jospt.2005.35.7.437] [Medline: 16108584]

9. Maclean N, Pound P, Wolfe C, Rudd A. Qualitative analysis of stroke patients' motivation for rehabilitation. BMJ 2000 Oct 28;321(7268):1051-1054. [Medline: 11053175]

10. Hoffman HG, Meyer WJ, Ramirez M, Roberts L, Seibel EJ, Atzori B, et al. Feasibility of articulated arm mounted Oculus Rift Virtual Reality goggles for adjunctive pain control during occupational therapy in pediatric burn patients. Cyberpsychol Behav Soc Netw 2014 Jun;17(6):397-401 [FREE Full text] [doi: 10.1089/cyber.2014.0058] [Medline: 24892204]

11. Schneider SM, Prince-Paul M, Allen MJ, Silverman P, Talaba D. Virtual reality as a distraction intervention for women receiving chemotherapy. Oncol Nurs Forum 2004;31(1):81-88. [doi: 10.1188/04.ONF.81-88] [Medline: 14722591]

12. Zimmerli L, Jacky M, Lünenburger L, Riener R, Bolliger M. Increasing patient engagement during virtual reality-based motor rehabilitation. Arch Phys Med Rehabil 2013 Sep;94(9):1737-1746. [doi: 10.1016/j.apmr.2013.01.029] [Medline: 23500181]

13. Thomas JS, France CR, Applegate ME, Leitkam ST, Walkowski S. Feasibility and Safety of a Virtual Reality Dodgeball Intervention for Chronic Low Back Pain: A Randomized Clinical Trial. J Pain 2016 Dec;17(12):1302-1317. [doi: 10.1016/j.jpain.2016.08.011] [Medline: 27616607]

14. Bandura A. Self-Efficacy: The Exercise of Control. New York: W.H. Freeman \& Company; 1997.

15. Moritz SE, Feltz DL, Fahrbach KR, Mack DE. The relation of self-efficacy measures to sport performance: a meta-analytic review. Res Q Exerc Sport 2000 Sep;71(3):280-294. [doi: 10.1080/02701367.2000.10608908] [Medline: 10999265]

16. Crombez G, Eccleston C, Van DS, Vlaeyen JWS, Karoly P. Fear-avoidance model of chronic pain: the next generation. Clin J Pain 2012 Jul;28(6):475-483. [doi: 10.1097/AJP.0b013e3182385392] [Medline: 22673479]

17. Lumley MA, Cohen JL, Borszcz GS, Cano A, Radcliffe AM, Porter LS, et al. Pain and emotion: a biopsychosocial review of recent research. J Clin Psychol 2011 Sep;67(9):942-968 [FREE Full text] [doi: 10.1002/jclp.20816] [Medline: 21647882]

18. Wertli MM, Rasmussen-Barr E, Weiser S, Bachmann LM, Brunner F. The role of fear avoidance beliefs as a prognostic factor for outcome in patients with nonspecific low back pain: a systematic review. Spine J 2014 May 01;14(5):816-36.e4. [doi: 10.1016/j.spinee.2013.09.036] [Medline: 24412032]

19. Fritz JM, George SZ, Delitto A. The role of fear-avoidance beliefs in acute low back pain: relationships with current and future disability and work status. Pain 2001 Oct;94(1):7-15. [Medline: 11576740]

20. Vlaeyen JW, Linton SJ. Fear-avoidance and its consequences in chronic musculoskeletal pain: a state of the art. Pain 2000 Apr;85(3):317-332. [Medline: 10781906]

21. Trost Z, France CR, Thomas JS. Pain-related fear and avoidance of physical exertion following delayed-onset muscle soreness. Pain 2011 Jul;152(7):1540-1547. [doi: 10.1016/j.pain.2011.02.038] [Medline: 21419575]

22. Mannion AF, O'Riordan D, Dvorak J, Masharawi Y. The relationship between psychological factors and performance on the Biering-Sørensen back muscle endurance test. Spine J 2011 Sep;11(9):849-857. [doi: 10.1016/j.spinee.2011.08.004] [Medline: 21903483]

23. Turk DC, Okifuji A. Detecting depression in chronic pain patients: adequacy of self-reports. Behav Res Ther 1994 Jan;32(1):9-16. [Medline: $\underline{\text { 8135727] }}$ 
24. George SZ, Valencia C, Beneciuk JM. A psychometric investigation of fear-avoidance model measures in patients with chronic low back pain. J Orthop Sports Phys Ther 2010 Apr;40(4):197-205. [doi: 10.2519/jospt.2010.3298] [Medline: 20357418]

25. Sullivan MJ, Thorn B, Haythornthwaite JA, Keefe F, Martin M, Bradley LA, et al. Theoretical perspectives on the relation between catastrophizing and pain. Clin J Pain 2001 Mar;17(1):52-64. [Medline: 11289089]

26. Sullivan MJL, Bishop SR, Pivik J. The Pain Catastrophizing Scale: Development and validation. Psychological Assessment 1995;7(4):524-532. [doi: 10.1037/1040-3590.7.4.524]

27. Hood A, Pulvers K, Carrillo J, Merchant G, Thomas M. Positive Traits Linked to Less Pain through Lower Pain Catastrophizing. Pers Individ Dif 2012 Feb;52(3):401-405 [FREE Full text] [doi: 10.1016/j.paid.2011.10.040] [Medline: 22199416]

28. Sturgeon JA, Zautra AJ. Psychological resilience, pain catastrophizing, and positive emotions: perspectives on comprehensive modeling of individual pain adaptation. Curr Pain Headache Rep 2013 Mar;17(3):317. [doi: 10.1007/s11916-012-0317-4] [Medline: 23338769]

29. Ankawi B, Slepian PM, Himawan LK, France CR. Validation of the Pain Resilience Scale in a Chronic Pain Sample. J Pain 2017 Aug;18(8):984-993. [doi: 10.1016/j.jpain.2017.03.013] [Medline: 28428092]

30. Roelofs J, Goubert L, Peters ML, Vlaeyen JWS, Crombez G. The Tampa Scale for Kinesiophobia: further examination of psychometric properties in patients with chronic low back pain and fibromyalgia. Eur J Pain 2004 Oct;8(5):495-502. [doi: 10.1016/j.ejpain.2003.11.016] [Medline: 15324781]

31. Houben RMA, Leeuw M, Vlaeyen JWS, Goubert L, Picavet HSJ. Fear of movement/injury in the general population: factor structure and psychometric properties of an adapted version of the Tampa Scale for Kinesiophobia. J Behav Med 2005 Oct;28(5):415-424. [doi: 10.1007/s10865-005-9011-x] [Medline: 16187010]

32. Bandura A. Guide for constructing self-efficacy scales. In: Pajares F, Urdan T. editors. Self-efficacy beliefs of adolescents. Greenwich, CT: Information Age Publishing; 2006:2-37.

33. Hardy C, Rejeski W. Not what, but how one feels: The measurement of affect during exercise. Journal of Sport and Exercise Psychology Sep 1989;11(3):304-317. [doi: 10.1155/2012/490647]

34. Applegate ME, France CR, Russ DW, Leitkam ST, Thomas JS. Sørensen test performance is driven by different physiological and psychological variables in participants with and without recurrent low back pain. Under review 2018.

35. Coorevits P, Danneels L, Cambier D, Ramon H, Vanderstraeten G. Assessment of the validity of the Biering-Sørensen test for measuring back muscle fatigue based on EMG median frequency characteristics of back and hip muscles. J Electromyogr Kinesiol 2008 Dec;18(6):997-1005. [doi: 10.1016/j.jelekin.2007.10.012] [Medline: 18396410]

36. Biering-Sørensen F. A prospective study of low back pain in a general population. I. Occurrence, recurrence and aetiology. Scand J Rehabil Med 1983;15(2):71-79. [Medline: 6223365]

37. Nicolaisen T, Jørgensen K. Trunk strength, back muscle endurance and low-back trouble. Scand J Rehabil Med 1985;17(3):121-127. [Medline: 2932794]

38. Sü̈̈den E, Ereline J, Gapeyeva H, Pääsuke M. Low back muscle fatigue during Sørensen endurance test in patients with chronic low back pain: relationship between electromyographic spectral compression and anthropometric characteristics. Electromyogr Clin Neurophysiol 2008;48(3-4):185-192. [Medline: 18551839]

39. Kankaanpää M, Laaksonen D, Taimela S, Kokko SM, Airaksinen O, Hänninen O. Age, sex, and body mass index as determinants of back and hip extensor fatigue in the isometric Sørensen back endurance test. Arch Phys Med Rehabil 1998 Sep;79(9):1069-1075. [Medline: 9749686]

40. Jørgensen K, Nicolaisen T. Two methods for determining trunk extensor endurance. A comparative study. Eur J Appl Physiol Occup Physiol 1986;55(6):639-644. [Medline: 2946578]

41. Alaranta H, Hurri H, Heliövaara M, Soukka A, Harju R. Non-dynamometric trunk performance tests: reliability and normative data. Scand J Rehabil Med 1994 Dec;26(4):211-215. [Medline: 7878396]

42. Van DS, Van RDML, Wyffels F, Van HL, Crombez G. No pain no gain? Pursuing a competing goal inhibits avoidance behavior. Pain 2012 Apr;153(4):800-804. [doi: 10.1016/j.pain.2011.12.015] [Medline: 22301333]

43. Demoulin C, Huijnen IPJ, Somville P, Grosdent S, Salamun I, Crielaard J, et al. Relationship between different measures of pain-related fear and physical capacity of the spine in patients with chronic low back pain. Spine J 2013 Sep;13(9):1039-1047. [doi: 10.1016/j.spinee.2013.02.037] [Medline: 23623193]

44. Demoulin C, Grosdent S, Bury T, Croisier J, Maquet D, Lehance C, et al. Cardiovascular Responses to Static Assessments of Trunk Muscles. Journal of Musculoskeletal Pain 2009 Nov 16;17(4):378-389. [doi: 10.3109/10582450903284786]

45. Descarreaux M, Lafond D, Jeffrey-Gauthier R, Centomo H, Cantin V. Changes in the flexion relaxation response induced by lumbar muscle fatigue. BMC Musculoskelet Disord 2008 Jan 24;9:10 [FREE Full text] [doi: 10.1186/1471-2474-9-10] [Medline: 18218087]

46. Evans K, Refshauge KM, Adams R. Trunk muscle endurance tests: reliability, and gender differences in athletes. J Sci Med Sport 2007 Dec;10(6):447-455. [doi: 10.1016/j.jsams.2006.09.003] [Medline: 17141568]

47. Ummunah JO, Ibikunle PO, Ezeakunne AC. Relationship between isometric endurance of back extensor muscles and selected anthropometric indices among some Nigerian undergraduates. J Back Musculoskelet Rehabil 2014;27(3):291-298. [doi: 10.3233/BMR-130446] [Medline: 24284276] 
48. Adedoyin RA, Mbada CE, Farotimi AO, Johnson OE, Emechete AAI. Endurance of low back musculature: normative data for adults. J Back Musculoskelet Rehabil 2011;24(2):101-109. [doi: 10.3233/BMR-2011-0282] [Medline: 21558615]

49. Mbada CE, Ayanniyi O, Adedoyin RA. Reference values of static back extensor muscle endurance in healthy Nigerian adults. Med Princ Pract 2009;18(5):345-350 [FREE Full text] [doi: 10.1159/000226285] [Medline: 19648754]

50. Clark BC, Manini TM, Thé DJ, Doldo NA, Ploutz-Snyder LL. Gender differences in skeletal muscle fatigability are related to contraction type and EMG spectral compression. J Appl Physiol (1985) 2003 Jun;94(6):2263-2272 [FREE Full text] [doi: 10.1152/japplphysiol.00926.2002] [Medline: 12576411]

51. Hicks AL, Kent-Braun J, Ditor DS. Sex differences in human skeletal muscle fatigue. Exerc Sport Sci Rev 2001 Jul;29(3):109-112. [Medline: 11474957$]$

52. Sadamoto T, Bonde-Petersen F, Suzuki Y. Skeletal muscle tension, flow, pressure, and EMG during sustained isometric contractions in humans. Eur J Appl Physiol Occup Physiol 1983;51(3):395-408. [Medline: 6685038]

53. Welle S, Tawil R, Thornton CA. Sex-related differences in gene expression in human skeletal muscle. PLoS One 2008 Jan 02;3(1):e1385 [FREE Full text] [doi: 10.1371/journal.pone.0001385] [Medline: 18167544]

54. Roatta S, Farina D. Sympathetic actions on the skeletal muscle. Exerc Sport Sci Rev 2010 Jan;38(1):31-35. [doi: 10.1097/JES.0b013e3181c5cde7] [Medline: 20016297]

55. Roepstorff C, Thiele M, Hillig T, Pilegaard H, Richter EA, Wojtaszewski JFP, et al. Higher skeletal muscle alpha2AMPK activation and lower energy charge and fat oxidation in men than in women during submaximal exercise. J Physiol 2006 Jul 01;574(Pt 1):125-138 [FREE Full text] [doi: 10.1113/jphysiol.2006.108720] [Medline: 16600998]

56. Kramer M, Dehner C, Hartwig E, Völker HU, Sterk J, Elbel M, et al. Intramuscular pressure, tissue oxygenation and EMG fatigue measured during isometric fatigue-inducing contraction of the multifidus muscle. Eur Spine J 2005 Aug;14(6):578-585 [FREE Full text] [doi: 10.1007/s00586-004-0857-3] [Medline: 15700188 ]

57. Dehner C, Schmelz A, Völker H, Pressmar J, Elbel M, Kramer M. Intramuscular pressure, tissue oxygenation, and muscle fatigue of the multifidus during isometric extension in elite rowers with low back pain. J Sport Rehabil 2009

Nov;18(4):572-581. [Medline: 20108857]

\section{Abbreviations}

BF: biceps femoris

BMI: body mass index

CES-D: Center for Epidemiological Studies-Depression

DOF: degree of freedom

EMG: electromyography

ERS: erector spinae

LBP: low back pain

MPF: median power frequency

PCS: Pain Catastrophizing Scale

PRS: Pain Resilience Scale

TSK: Tampa Scale for Kinesiophobia

TSK-G: Tampa Scale for Kinesiophobia-General Population

TTF: time to task failure

Edited by G Eysenbach; submitted 28.03.18; peer-reviewed by B Atzori, M Alshehri; comments to author 26.04.18; revised version
received 20.06.18; accepted 21.06.18; published 10.09.18
Please cite as:
Applegate ME, France CR, Russ DW, Leitkam ST, Thomas JS
Determining Physiological and Psychological Predictors of Time to Task Failure on a Virtual Reality Sørensen Test in Participants
With and Without Recurrent Low Back Pain: Exploratory Study
JMIR Serious Games 2018;6(3):e10522
URL: $\underline{\text { http://games.jmir.org/2018/3/e10522/ }}$
doi: $\underline{10.2196 / 10522}$
PMID: $\underline{30201604}$

CMegan E Applegate, Christopher R France, David W Russ, Samuel T Leitkam, James S Thomas. Originally published in JMIR Serious Games (http://games.jmir.org), 10.09.2018. This is an open-access article distributed under the terms of the Creative Commons Attribution License (https://creativecommons.org/licenses/by/4.0/), which permits unrestricted use, distribution, and reproduction in any medium, provided the original work, first published in JMIR Serious Games, is properly cited. The complete 
bibliographic information, a link to the original publication on http://games.jmir.org, as well as this copyright and license information must be included. 